Bull. Mater. Sci., Vol. 8, No. 1, February 1986, pp. 13-21. (C) Printed in India.

\title{
Microstructural and dielectric behaviour of glass ceramics in the system $\mathrm{PbO}-\mathrm{BaO}-\mathrm{TiO}_{2}-\mathrm{B}_{2} \mathrm{O}_{3}-\mathrm{SiO}_{2}$
}

\author{
OM PARKASH, DEVENDRA KUMAR* and R RAJGOPALAN
}

School of Materials Science and Technology and *Department of Ceramic Engineering, Institute of Technology, Banaras Hindu University, Varanasi 221005 , India

MS received 25 October 1985

\begin{abstract}
Glasses in the system $\mathrm{PbO}-\mathrm{BaO}-\mathrm{TiO}_{2}-\mathrm{B}_{2} \mathrm{O}_{3}-\mathrm{SiO}_{2}$ with and without $\mathrm{P}_{2} \mathrm{O}_{5}$ as nucleant have been prepared. The glass samples were ceramized based on DTA studies. The ferroelectric phase crystallizing out has been found to be $\mathrm{BaTiO}_{3}$ from XRD. The optical and scanning electron micrographs show the presence of $\mathrm{BaTiO}_{3}$ as major phase. In these glass ceramic samples, dielectric constant and dissipation factor are approximately constant with temperature and frequency upto the glass transition temperature $T_{g}$ and thereafter increase sharply with temperature and finally level off. The addition of $\mathrm{P}_{2} \mathrm{O}_{5}$ as nucleant and molar ratio of $(\mathrm{PbO}+\mathrm{BaO})$ to $\mathrm{TiO}_{2}$ has marked influence on the dielectric behaviour and composition of ferroelectric phase crystallizing out.
\end{abstract}

Keywords. Microstructure; dielectric behaviour; glass ceramic; differential thermal analysis.

\section{Introduction}

There has been considerable interest in the last two decades to produce ferroelectric crystals in a glassy matrix by glass ceramic process (Bergeron 1961; Herczog 1964; Grossman and Isard 1969a, b; Borreli and Layton 1971; Kokubo and Tashiro 1973/74; Herczog 1984). This is an efficient way of producing an uniform pore-free and finegrained microstructure which is highly desirable in ferroeleotric materials. Bergeron (1964) was the first to develop $\mathrm{PbTiO}_{3}$ crystals from the glasses in the system $\mathrm{PbO}$ $\mathrm{TiO}_{2}-\mathrm{B}_{2} \mathrm{O}_{3}$. Various workers have since attempted to produce solid solution crystals for obtaining the desired ferroelectric properties by this process. Herczog (1964) reported that the effect of adding $\mathrm{CaO}, \mathrm{SrO}, \mathrm{PbO}$ etc to the glass system $\mathrm{BaO}-\mathrm{TiO}_{2}$ $\mathrm{B}_{2} \mathrm{O}_{3}-\mathrm{SiO}_{2}$ on the ferroelectric properties of glass ceramics was the same as that found in the ceramic $\mathrm{BaTiO}_{3}$ solid solution. However, no details were reported. Grossman and Isard (1969b) studied the crystallization of glasses in the system PbO-BaO-TiO $\mathrm{B}_{2} \mathrm{O}_{3}$. They reported the formation of $\mathrm{PbTiO}_{3}$ using the $\mathrm{x}$-ray diffraction technique. Such procedures may not be powerful tools in establishing the formation of solid solutions since shifts in the interplanar spacings resulting from the formation of solid solution may not be distinguished from the shifts arising from the strain effects due to crystal clamping (Grossman and Isard 1969a; Lynch and Shelby 1984).

Hence, Lynch and Shelby (1984) used dilatometric method to determine the ferroelectric-paraelectric transition temperature and thus for identification of ferroelectric phase. They established the formation of $\mathrm{PbTiO}_{3}$ only in the system $\mathrm{PbO}$ $\mathrm{BaO}-\mathrm{TiO}_{2}-\mathrm{B}_{2} \mathrm{O}_{3}$. It is noted that they studied almost the same compositions as studied earlier by Grossman and Isard (1969). Both these groups did not use the requisite 
amount of $\mathrm{TiO}_{2}$ to crystallize both $\mathrm{BaTiO}_{3}$ and $\mathrm{PbTiO}_{3}$ either as independent phases or in the solid solution form.

It is quite likely that the formation of ferroelectric phase in either of these forms during ceramization process depends on the initial glass composition i.e., $\mathrm{BaO}$ to $\mathrm{PbO}$ ratio and/or $(\mathrm{BaO}+\mathrm{PbO})$ to $\mathrm{TiO}_{2}$ ratio. This paper reports the results of investigation of crystalline phases developed in the glass system $\mathrm{BaO}-\mathrm{PbO}-\mathrm{TiO}_{2}-\mathrm{B}_{2} \mathrm{O}_{3}-\mathrm{SiO}_{2}$ during ceramization process. We have chosen an initial glass composition in which both $\mathrm{BaO}$ to $\mathrm{PbO}$ and $(\mathrm{BaO}+\mathrm{PbO})$ to $\mathrm{TiO}_{2}$ ratios are equimolar. The effect of addition of $\mathrm{P}_{2} \mathrm{O}_{5}$ as nucleant in the glass on the ceramization and dielectric behaviour is also reported.

\section{Experimental}

AR grade $\mathrm{PbO}, \mathrm{BaCO}_{3}, \mathrm{TiO}_{2}, \mathrm{SiO}_{2}, \mathrm{H}_{3} \mathrm{BO}_{3}$ and $\left(\mathrm{NH}_{4}\right)_{2} \mathrm{HPO}_{4}$ were used in the preparation of glasses. Batches weighing $50 \mathrm{~g}$ were mixed in an agate mortar using acetone. The mixed powders were melted in alumina crucibles at $1375 \mathrm{~K}$ and kept for about 30 minutes with intermittant stirring for homogenization and removal of bubbles. The melts were poured into an aluminium mold quickly and pressed by another aluminium plate to produce transparent glass samples. The cast glasses were immediately annealed by transferring to another preheated furnace kept at $475 \mathrm{~K}$. The composition of the glasses prepared is given in table 1.

The amorphosity of glasses was confirmed by $x$-ray diffraction. Differential thermal analysis (DTA) of glasses was done using 505 MOM derivatograph to find the glass transition, $T_{g}$, nucleation, $T_{N}$ and growth temperature of possible crystalline phases which would form during ceramization. Glasses were given two-stage heat treatments corresponding to nucleation and growth temperatures determined by DTA, following the procedure indicated below. Glass samples were introduced into a furnacepreheated to the nucleation temperature and held for 30 minutes following which the temperature was raised quickly to the growth temperature. They were kept at growth temperatures for $3-12 \mathrm{hr}$ and then slowly withdrawn from the furnace and $\mathrm{x}$-ray diffraction patterns of the resulting glass ceramic samples were taken using Rich and Seifert Iso-Debyeflex 2002 diffractometer employing $\mathrm{Cu}-\mathrm{K}_{\alpha}$ radiation.

For microstructural studies the samples were polished and etched using warm $10 \%$ $\mathrm{HCl}$ solution. The microstructures were taken using Zeiss optical microscope (model 415) and Phillips scanning electron microscope (model PSEM 500). Dielectric constant and loss tangent were measured in the frequency range $1 \mathrm{kHz}$ to $100 \mathrm{kHz}$ from room temperature to $775 \mathrm{~K}$ using General Radio capacitance bridge (Model 1615).

\section{Results and discussion}

DTA plots of glass compositions 1 and 2 are shown in figure 1. Both the glasses showed glass transition around $575 \mathrm{~K}$. There is an endothermic peak around $810 \mathrm{~K}$ and two

Table 1. Composition of glasses ( $\mathrm{mol} \%$ )

\begin{tabular}{ccccccc}
\hline Glass No. & $\mathbf{P b O}$ & $\mathrm{BaO}$ & $\mathrm{TiO}_{2}$ & $\mathrm{SiO}_{2}$ & $\mathbf{B}_{2} \mathrm{O}_{\mathbf{3}}$ & $\mathbf{P}_{2} \mathrm{O}_{5}$ \\
\hline 1 & 21 & 21 & 42 & 6 & 10 & 0 \\
2 & 21 & 21 & 42 & 4 & 10 & 2 \\
\hline
\end{tabular}




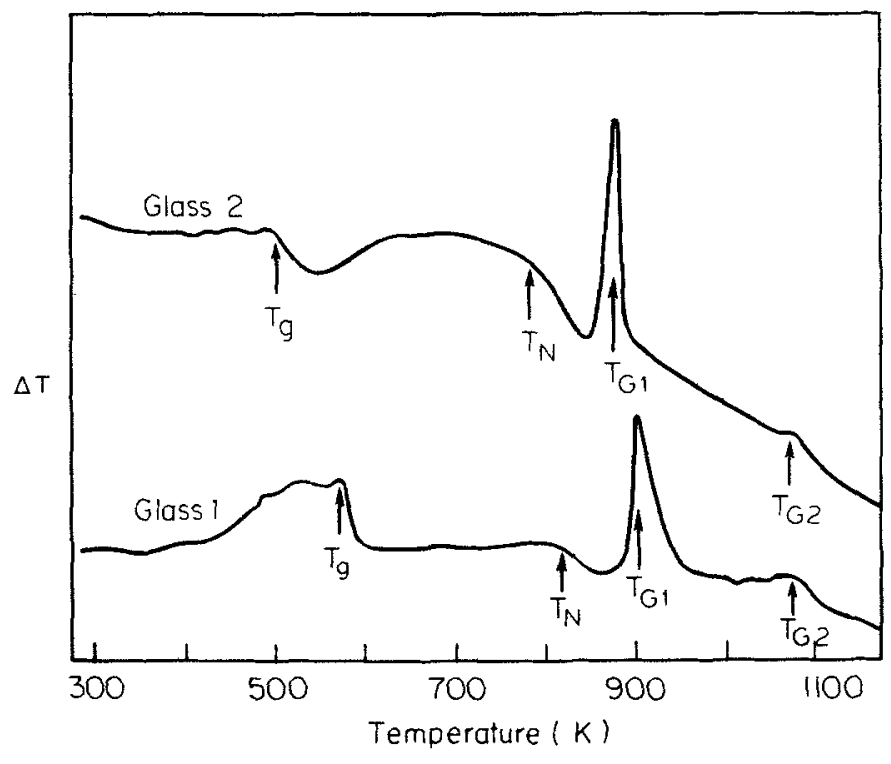

Figure 1. DTA plot of glasses 1 and 2 .

exothermic peaks at $900 \mathrm{~K}$ and $1075 \mathrm{~K}$ in glass no 1 . The endothermic peak is assigned to nucleation temperature $T_{N}$ and the two exothermic peaks to two growth temperatures, $T_{G 1}$ and $T_{G 2}$ of two crystalline phases which develop during heat treatment. The corresponding temperatures for glass no 2 are 780,880 and $1060 \mathrm{~K}$ respectively. Based on these results, glasses (nos 1 and 2) were subjected to various heat treatments schedules. X-ray diffraction of sample no $1 \mathrm{~A}$ (heat-treated at $T_{N}$ for $30 \mathrm{~min}$ and at $T_{\mathrm{G} 1}$ for $3 \mathrm{hrs}$ ) indicated the formation of only $\mathrm{BaTiO}_{3}$ phase during ceramization. However, the sample $2 \mathrm{~A}$ (heat treated at $T_{N}$ for $30 \mathrm{~min}$ and at $T_{G 1}$ for $3 \mathrm{hrs}$ ) of glass no. 2 indicated the presence of a small amount of another phase besides $\mathrm{BaTiO}_{3}$ which is the major constituent. Hence $T_{G 1}$ corresponds to growth of $\mathrm{BaTiO}_{3}$ phase, while $T_{G 2}$ represents the growth temperature of a second crystalline phase. The presence of $\mathrm{BaTiO}_{3}$ is confirmed by DTA of glass ceramic sample no. 2A. The DTA shows a broad exothermic peak at around $375 \mathrm{~K}$ which represents the Curie temperature of $\mathrm{BaTiO}_{3}$.

$\mathrm{X}$-ray diffraction studies of other glass ceramic samples heat-treated at higher temperatures $975 \mathrm{~K} / 1075 \mathrm{~K}$, show the presence of both $\mathrm{BaTiO}_{3}$ as well as a second phase which could not be identified. Grossman and Isard (1969b) and Lynch and Shelby (1984) reported the formation of only $\mathrm{PbTiO}_{3}$ in the system $\mathrm{PbO}-\mathrm{BaO}-\mathrm{TiO}_{2}$ $\mathrm{B}_{2} \mathrm{O}_{3}-\mathrm{SiO}_{2}$ where $(\mathrm{PbO}+\mathrm{BaO})$ to $\mathrm{TiO}_{2}$ ratio was very near to $2: 1$. In the present study the above ratio is $1: 1$ and it is found that the ferroelectric phase formed is $\mathrm{BaTiO}_{3}$. Although XRD alone cannot determine the formation of solid solution, it can definitely distinguish between $\mathrm{BaTiO}_{3}$ and $\mathrm{PbTiO}_{3}$. The second strongest line of $\mathrm{PbTiO}_{3}$ is missing in $\mathrm{BaTiO}_{3}$. Thus it appears that $(\mathrm{PbO}+\mathrm{BaO})$ to $\mathrm{TiO}_{2}$ ratio in base glass composition influences the composition of ferroelectric phase that forms on crystallization.

Optical micrographs of the sample $1 \mathrm{~A}, 1 \mathrm{~B}$ and $2 \mathrm{~A}$ are shown in figure 2. The micrograph of sample $1 \mathrm{~A}$ (figure 2a) shows that it contains uniform dispersion of fine- 


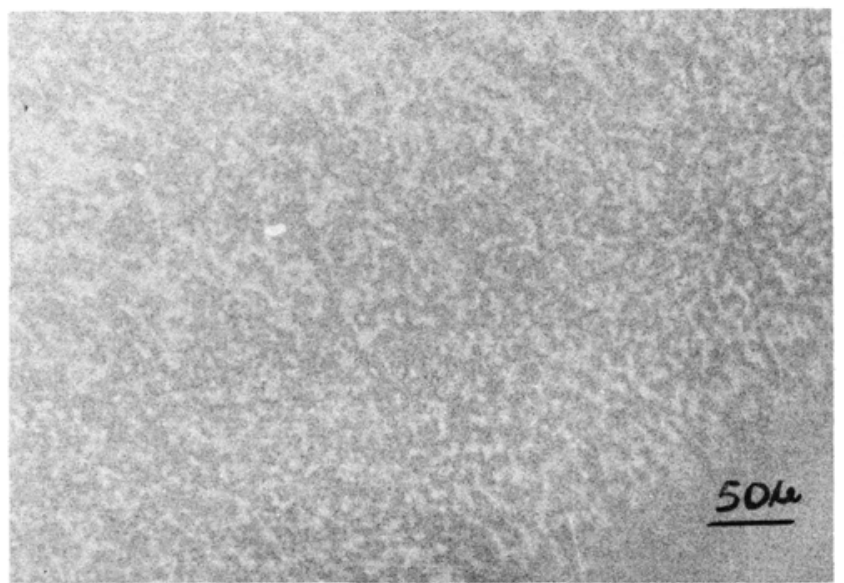

(a)

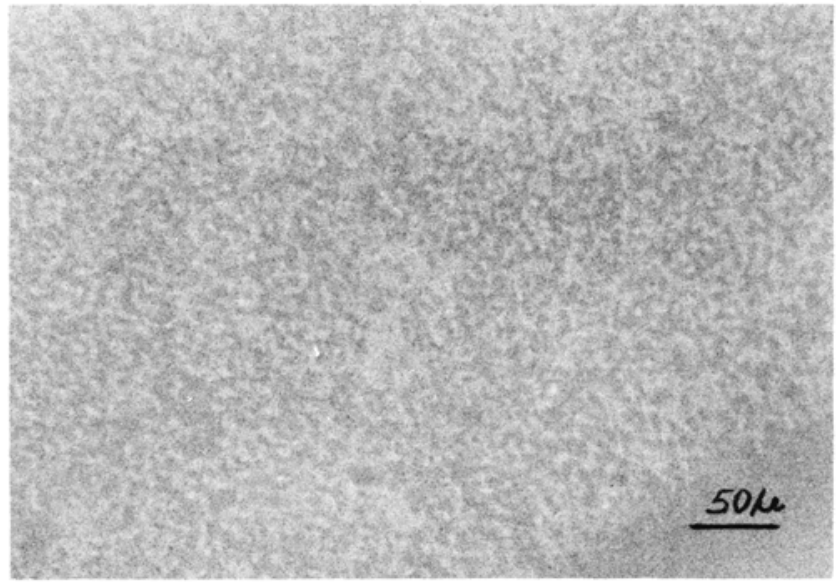

(b)

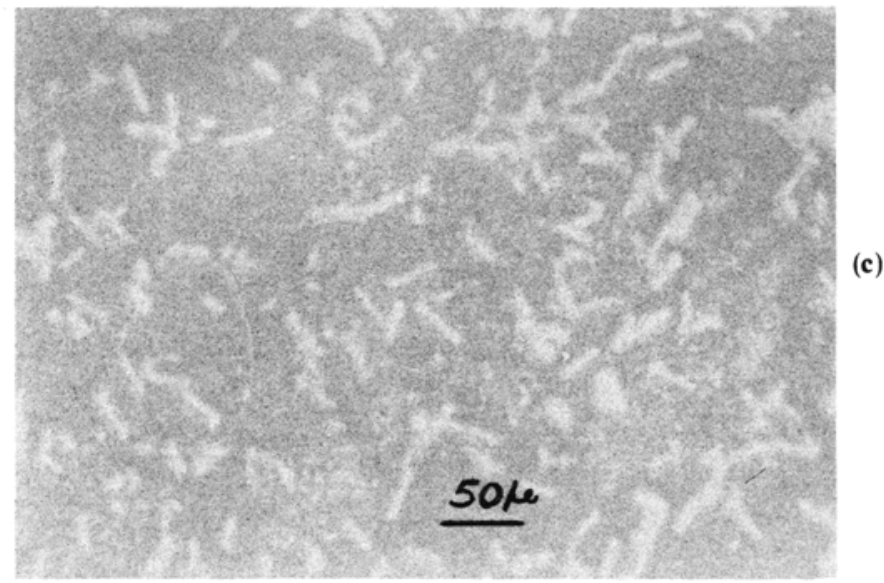

Figure 2. Optical micrograph of the glass ceramic sample (a) $1 \mathrm{~A}$ heat-treated at $810 \mathrm{~K}$ for $30 \mathrm{~min}$ and $900 \mathrm{~K}$ for $3 \mathrm{hrs}$ (b) sample $1 \mathrm{~B}$ heat-treated at $875 \mathrm{~K}$ for $30 \mathrm{~min}$ and $1075 \mathrm{~K}$ for $3 \mathrm{hr}$ (c) $2 \mathrm{~A}$ heat-treated at $780 \mathrm{~K}$ for $30 \mathrm{~min}$ and $880 \mathrm{~K}$ for $3 \mathrm{hrs}$. 

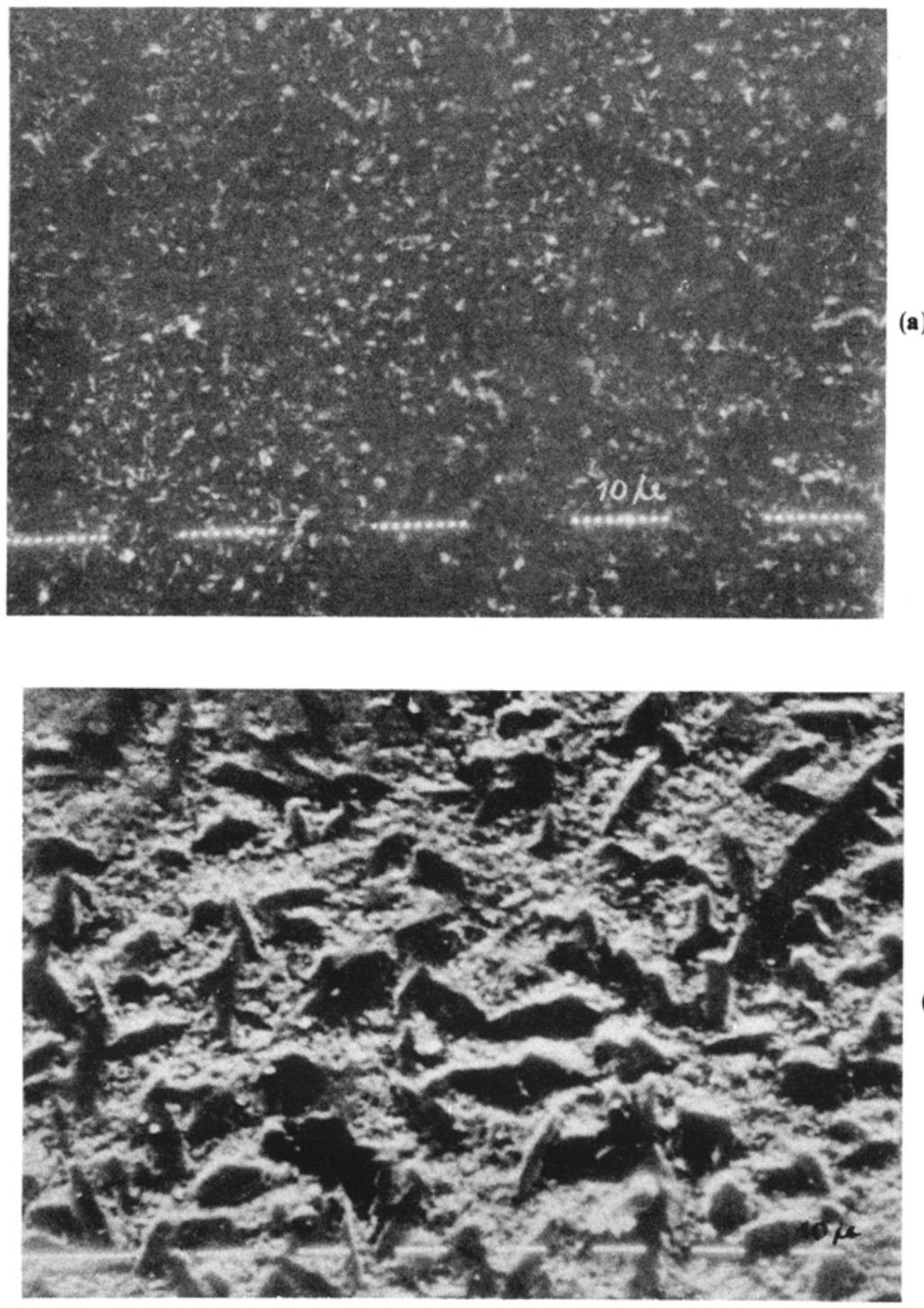

(b)

Figure 3. Scanning electron micrograph of sample (a) 1 A at magnification $1500 \times$ (b) $2 B$ heat-treated at $975 \mathrm{~K}$ for $12 \mathrm{hr}$ at magnification $750 \times, 10 \mu \mathrm{m}$.

grained $\mathrm{BaTiO}_{3}$ crystallites having an average size of $<1 \mu \mathrm{m}$. On the other hand, sample 1B (figure $2 \mathrm{c}$ ) which was obtained by heat treatment at higher temperature contains crystallites of second phase having an average particle size of $30 \mu \mathrm{m}$ along with a fine dispersion of $\mathrm{BaTiO}_{3}$. These results are in conformity with the results of $\mathrm{x}$-ray diffraction which indicated the formation of only $\mathrm{BaTiO}_{3}$ phase in sample $1 \mathrm{~A}$ and of $\mathrm{BaTiO}_{3}$ and a second phase in 1B. The optical micrograph of sample $2 \mathrm{~A}$ is similar to that of sample $1 \mathrm{~A}$ except that the size and particle distribution are different. Figures $3 \mathrm{a}$ and $3 \mathrm{~b}$ show scanning electron micrographs of samples $1 \mathrm{~A}$ and $2 \mathrm{~B}$ respectively. As is clear from the micrograph (figure 3a), sample $1 \mathrm{~A}$ contains a uniform dispersion of fine- 


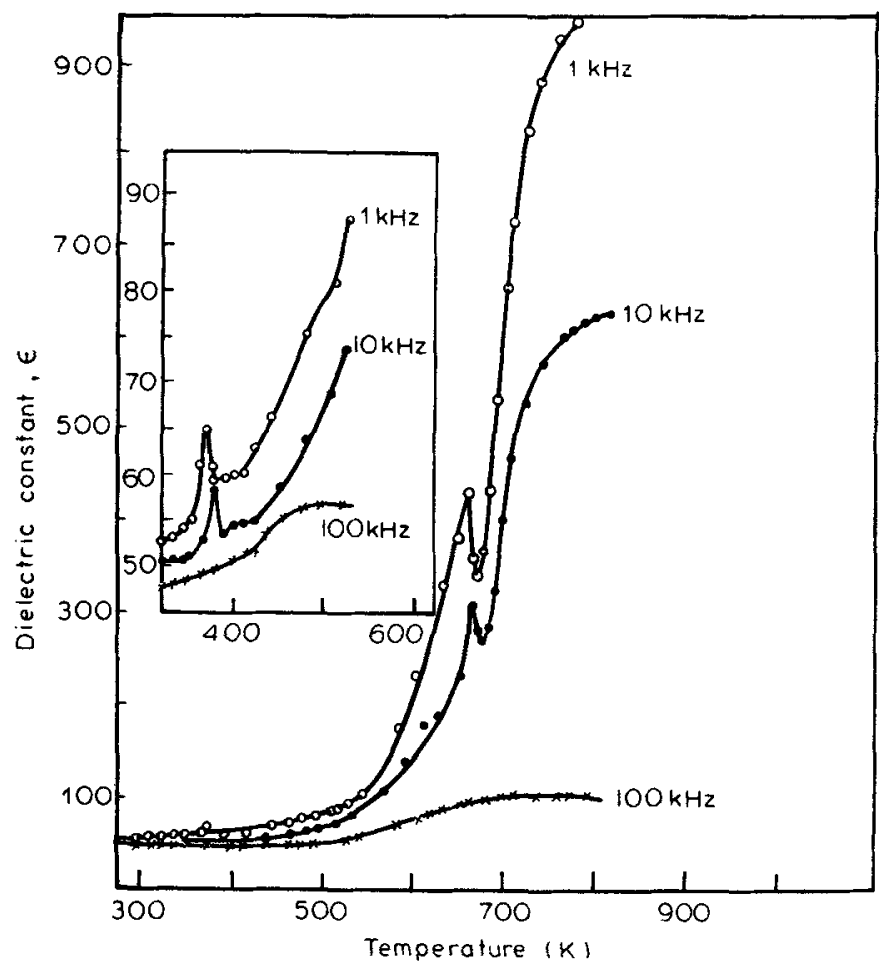

Figure 4. Variation of dielectric constant $\varepsilon$ with temperature at $1 \mathrm{kHz}, 10 \mathrm{kHz}$ and $100 \mathrm{kHz}$ for sample 1A. The insert shows the same variation on enlarged Y-scale.

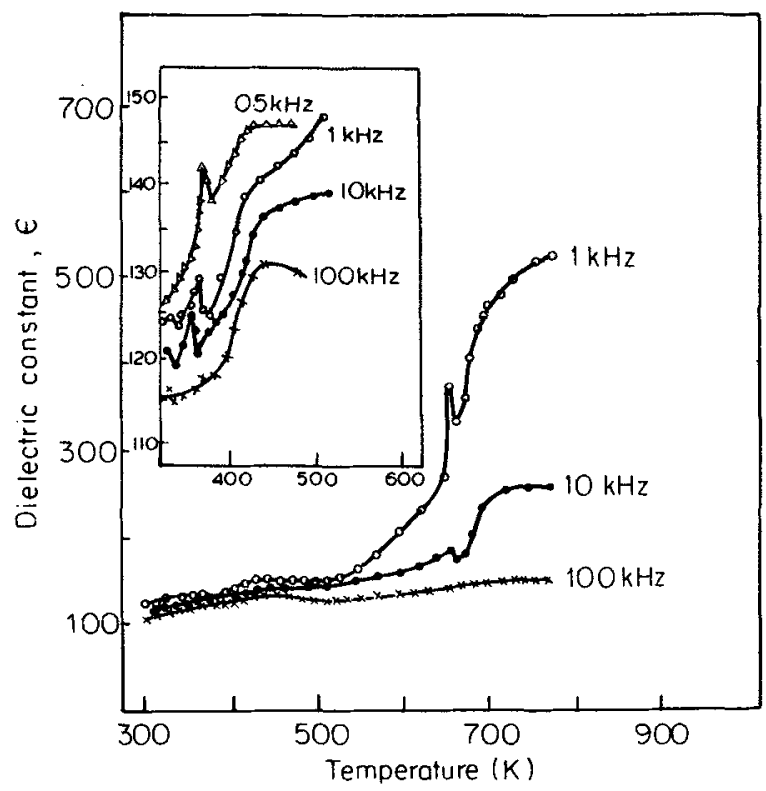

Figure 5. Variation of dielectric constant $\varepsilon$ with temperature at different frequencies for sample $2 \mathrm{~A}$. Insert shows the same variation on enlarged $\mathrm{Y}$-scale. 


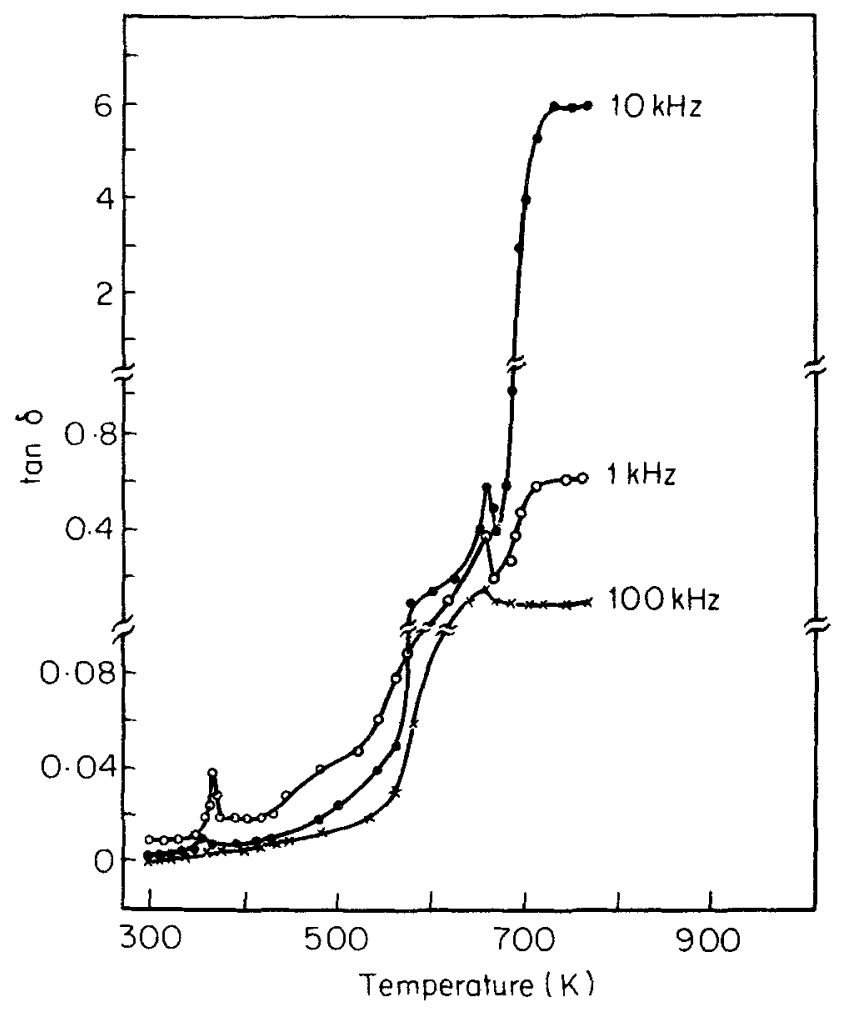

Figure 6. Variation of dissipation factor $D$ with temperature at different frequencies for $1 A$.

grained $\mathrm{BaTiO}_{3}$ phase. In sample 2B which was given a single-stage heat treatment at $975 \mathrm{~K}$ for $12 \mathrm{hr}$, there are a few big crystals of second phase which grew with welldefined angles and edges having an approximate size of $20 \mu \mathrm{m}$ and a very fine dispersion of $\mathrm{BaTiO}_{3}$ particles having a size less than $1 \mu \mathrm{m}$.

The variation of dielectric constant of samples $1 \mathrm{~A}$ and $2 \mathrm{~A}$ as a function of temperature at $1 \mathrm{kHz}, 10 \mathrm{kHz}$ and $100 \mathrm{kHz}$ is shown in figures 4 and 5 respectively. Variation of dissipation factor, $\tan \delta$, with temperature at these three frequencies is shown in figures 6 and 7 respectively. There is an anomaly in dielectric constant at around $375-400 \mathrm{~K}$ in these samples as is clear from the inserts of figures 4 and 5. Similar anomaly is also noticed in the corresponding dissipation factor at the same temperature. This temperature represents the Curie temperature of $\mathrm{BaTiO}_{3}$. There is another anomaly in the dielectric constant at around $675 \mathrm{~K}$ which was also observed in the as-cast glasses. This dielectric behaviour of all the samples is reproducible under repeated heating and cooling cycle. This peak thus does not represent any ferroelectricparaelectric transition of any crystalline phase. The origin of this anomaly is under investigation.

The dielectric constant and the dissipation factor do not increase significantly with temperature up to $525 \mathrm{~K}$ for sample $1 \mathrm{~A}$ and upto $575 \mathrm{~K}$ for sample $2 \mathrm{~A}$. Upto this temperature the variation of dielectric constant and dissipation factor with frequency is linear and quite small. Beyond this temperature, the dielectric constant increases sharply and levels off at higher temperatures (figures 4 and 5). This increase in dielectric 


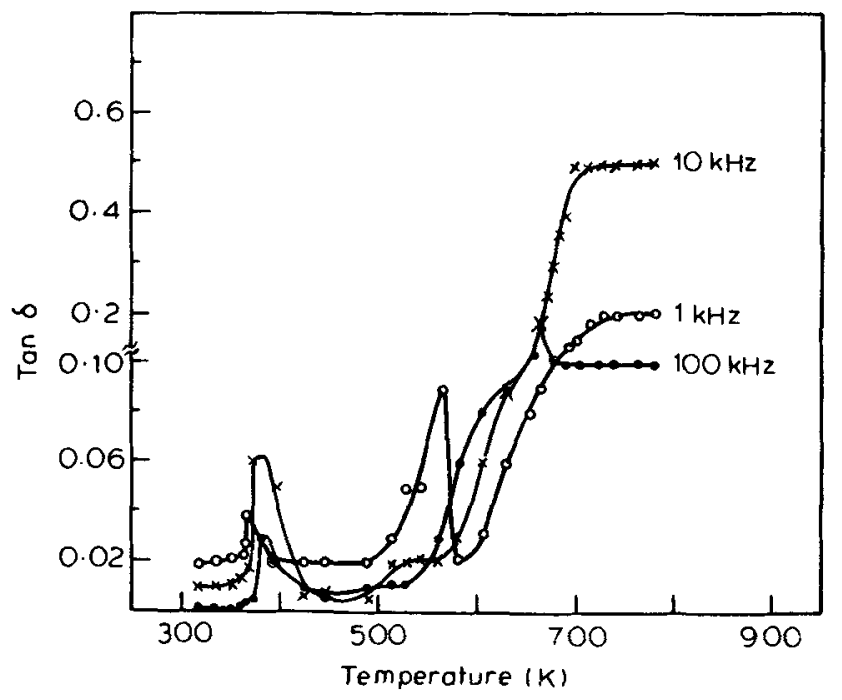

Figure 7. Variation of dissipation factor $D$ with temperature of sample $2 A$ at different frequencies.

constant is less at $100 \mathrm{kHz}$ and increases with decreasing frequency. The dissipation factor also increases sharply beyond this temperature. At higher temperatures, the dissipation factor appears to show a maximum between 1 and $100 \mathrm{kHz}$ near $10 \mathrm{kHz}$. It is observed that this temperature upto which dielectric constant and dissipation factor remain almost constant with frequency and temperature is the same as the glass transition temperature, $T_{g}$, of respective samples determined from DTA. This approximately constant value of dielectric constant below $T_{g}$ can be understood in terms of the small grain size of $\mathrm{BaTiO}_{3}$ and restraining effect of rigid glassy matrix. Upto $T_{g}$, the polarization remain small as the dipoles cannot respond easily to the external electric field. After the $T_{g}$, the glass matrix softens, whereby the dipoles start responding to external electric field giving a high value of dielectric constant. The maxima in dissipation factor at around $10 \mathrm{kHz}$ can be understood in terms of space charge polarization relaxation phenomena associated with this reorientation of dipoles.

Comparing the dielectric behaviour of samples $1 \mathrm{~A}$ and $2 \mathrm{~A}$ (containing $\mathrm{P}_{2} \mathrm{O}_{5}$ ) it is observed that the effect of nucleant $\mathrm{P}_{2} \mathrm{O}_{5}$ is (i) to increase the low temperature dielectric constant and (ii) to decrease the high temperature dielectric constant and dielectric loss. The first may be attributed to the large volume fraction of $\mathrm{BaTiO}_{3}$ phase precipitated in sample $2 \mathrm{~A}$. The latter may be understood in terms of the presence of the second phase along with the $\mathrm{BaTiO}_{3}$-phase restricting the orientation of dipoles.

\section{Conclusions}

The present studies indicate that the molar ratios of $\mathrm{PbO}$ to $\mathrm{BaO}$ and $(\mathrm{PbO}+\mathrm{BaO})$ to $\mathrm{TiO}_{2}$ in the initial glass composition have a marked influence on the composition of ferroelectric phase and addition of a nucleant such as $\mathrm{P}_{2} \mathrm{O}_{5}$ has profound effect on the microstructural and dielectric behaviour of glass ceramic system. 


\section{Acknowledgements}

The authors are thankful to Prof. P Ramachandrarao for stimulating discussions and comments and to Advanced Centre for Materials Science, IIT, Kanpur for providing some facilities during the study.

\section{References}

Bergeron C G 1961 Crystallization of perovskite lead titanate from glass, Ph.D. Thesis, University of Illinois Borrelli N F and Layton M M 1971 J. Non-Cryst. Solids 6197

Grossman D G and Isard J O 1969a J. Mater. Sci. 41059

Grossman D G and Isard J O 1969b J. Am. Ceram. Soc. 52230

Herczog A 1964 J. Am. Ceram. Soc. 47107

Herczog A 1984 J. Am. Ceram. Soc. 67484

Kokubo T and Tashiro M 1973/74 J. Non-Cryst. Solids 13328

Lynch S M and Shelby J E 1984 J. Am. Ceram. Soc. 67424 